\title{
Faculty Teaching Practices and Perceptions: Comparative Analysis Based on Time Spent Lecturing
}

The University of British Columbia-Vancouver (UBC-V) implemented a campus-wide survey of faculty teaching practices and perceptions. All 11 Faculties participated, resulting in a total of 1177 responses for an overall response rate of $24 \%$. We compared response patterns of faculty who reported spending less than 25\%, between 26-50\%, between 51-75\%, and more than 75\% of classroom time lecturing. Using this breakdown, we analysed survey responses related to in and out-of-class practices and expectations for students, use of teaching assistant time, participation in professional development opportunities, and perceptions of whether the institution valued teaching. Participants across quadrants reported employing a wide range of teaching methods irrespective of years of experience and class size. Our findings outline the range of teaching practices employed by faculty at a large research-intensive Canadian institution and may provide baseline information for institutions of similar scale and focus.

$\mathrm{O}$ ver the past decade, there has been considerable interest in understanding the most prevalent instructional practices in higher education, as well as their relative impact on student learning (Ambrose et al., 2010; Bain, 2004; Buskist \& Groccia, 2011; Nilson, 2010). It has been reported, for instance, that despite the growing body of research lauding the impact of non-lecture based instructional practices on learning, lecture continues to be the dominant practice in many university classrooms (Freeman et al., 2014; Michael, 2006; Prince, 2004). In 1980, Blackburn, Pellino, Boberg, and O'Connell surveyed faculty from 24 institutions and found $78 \%$ of faculty reported lecture as their principal instructional method. This finding was echoed by Thielens (1987) who surveyed over 800 faculty at 80 U.S. institutions, exploring the percent of time spent lecturing in relation to variables such as academic discipline, gender of the instructor, and class size. Overall, faculty reported that $80 \%$ of class time was devoted to lecture. Studies by Lammers and Murphy (2002) and Smith, Vinson, Smith, Lewin, and Stetzer (2014), both of which compared survey responses to observations of classroom practice, concluded that both instructor estimates and observed practices were in high agreement and lecture remains the primary method of instruction at the universities studied.

A number of studies have explored why faculty select lecture as the primary mode of instruction (Henderson, Beach, \& Finkelstein, 2011; Miller, Martineau, \& Clark, 2000), and it has been suggested that it is unlikely a single factor that determines what instructional practice a faculty member chooses to implement (Lammers \& Murphy, 2002). Instead, it is believed that there is a complex relationship between instructor factors, discipline factors, and class factors that may lead faculty to choose specific instructional methods (Henderson, 
Beach, \& Finkelstein, 2011; Miller, Martineau, \& Clark, 2000). For instance, Blumberg (2011), Boice (1992), and Kane, Sandretto, and Heath (2002) indicate that many faculty have little or no formal education on instructional practices or methods to prepare them for university teaching and, consequently, rely on what is referred to as an "apprenticeship of observation" during their years as students (Lortie, 1975). As a result, experience as a student may be one of the most influential factors shaping faculty instructional choices (Hiebert \& Stigler, 2000), leading faculty to "teach how they were taught, using largely passive lectures" (Blumberg, 2011, p. 27). According to Goffe and Kauper (2014), little personal exposure to non-lecture based instructional methods may result in faculty lacking the confidence to try other instructional practices and a perception of the risk as a barrier to implementation. In addition, faculty beliefs about teaching, such as whether the goal of teaching is knowledge transmission or facilitating learning, likely also influence which practices they choose. Faculty who believe the goal of teaching is knowledge transmission are more likely to lecture and those believing the purpose is facilitating learning are more likely to employ active learning (Kane et al., 2002). Faculty beliefs about the efficacy of instructional methods also influence their decision regarding which teaching practices to employ in the classroom with faculty generally adopting the practices they feel will best help students learn (Ballantyne, Bain, \& Packer, 1999). In their 2014 study of 340 economics instructors, Goffe and Kauper found that one-third believed students learned best from lecture.

It has also been hypothesized that certain course characteristics, such as discipline or class size, lead faculty to lecture for efficiency (Goffe \& Kauper, 2014). Theilens (1987) found the percent of time spent on lecture was higher in disciplines such as the physical sciences, life sciences, and mathematics. Also, Ballantyne et al. (1999) and Smeby (1996) concluded that academics in technological disciplines spend much of their time on lectures, whereas those in the humanities are more likely to include seminars and tutorials in their teaching practices. In her review of the literature, Newmann (2001) concluded that disciplinary culture and knowledge have a direct impact on the decisions faculty make about teaching practices. In addition, several studies have found a positive relationship between class size and the use of lecture (Lammers \& Murphy, 2002; Smith et al., 2014; Thielens, 1987). However, Smith et al. (2014) studied only STEM disciplines and found a wide range of teaching practices were employed to supplement lecture in both large and small enrolment courses.

It is important to note that there is evidence that suggests lecture may be equal or superior to other instructional practices when the objective is learning factual information (Bligh, 2000; Costin, 1972) and that lecture "can be as effective as any other instructional strategy so long as it is appropriately suited to the intended learning outcomes and is pedagogically planned and delivered" (Saroyan \& Snell, 1997, p. 102). In addition, Lammers and Murphy (2002) found faculty who lectured more often made more efficient use of classroom time compared to those employing active learning techniques, where $15 \%$ of classroom time was spent on non-instructional activities. Furthermore, research has indicated that significant student learning most likely results when faculty employ a variety of instructional practices, rather than relying exclusively on one approach (Bligh, 2000; Costin, 1972).

Regardless of effectiveness, there is a tendency in the literature to classify instructors as relying almost exclusively either on lecture or on active learning (Smith et al., 2014). Many previous studies of instructional practice focus on how broadly or extensively lecture is employed by faculty (Blackburn et al., 1980; Thielens, 1987), without exploring the prevalence of other instructional practices (Lammers \& Murphy, 2002). Further, most studies of active learning techniques tend to classify faculty as either employing said techniques or lecturing exclusively (Smith et al., 2014), ignoring the possibility that faculty regularly employ a range of practices. Even the Higher Education Research Institute Faculty Survey (Eagan et al., 2014), which aims to provide institutions with a "comprehensive, research-based picture of key aspects of the faculty experience", provides only limited insight into how extensively various instructional practices are used. While the survey does ask faculty if they have engaged 
in a variety of instructional practices, it does not ask about the amount of time dedicated to each. It is clear, however, the tendency to portray faculty as either lecturing exclusively or not at all paints an inaccurate and overly simplified portrait of teaching at the university level (Smith et al., 2014).

It is worth noting that most existing research on faculty instructional practices focuses on either institutions in the United States (Blackburn et al., 1980; Lammers \& Murphy, 2002; Smith et al., 2014; Thielens, 1987), or in STEM fields (Smith et al., 2014), or assesses the efficacy of specific practices (meta-analysis in Freeman et al., 2014; Michael, 2006; Prince, 2004), rather than exploring the broad range of practices employed by faculty in the course of their teaching. Additional research exploring teaching practices across a broad range of disciplines and in institutions beyond the Unites States could add to our overall understanding of postsecondary teaching and learning. What is more, research seeking to portray a more accurate understanding of the range of teaching practices employed by individual faculty could add meaningful complexity to a currently overly simplified picture of postsecondary teaching.

In this paper, we supplement existing research on teaching practices by exploring data from a broad range of disciplines at a large, researchintensive Canadian institution. We employ a primarily quantitative approach to provide a detailed description of the range of teaching practices employed and the perceptions related to those practices. Specifically, we address the following research questions:

(1) Is there a range of instructional practices employed across the university or do specific practices emerge as dominant?

(2) What are the implications of minimal and extensive time lecturing on other instructional practices and faculty expectations?

(3) Are there differences in uptake of professional development and perceptions of institutional support for teaching among faculty who spend minimal and extensive time lecturing?

We seek to better understand what teaching practices are employed in our context so we might better support faculty by identifying possible areas for professional development. We also discuss whether our findings mirror those from studies conducted in other institutions and contexts and whether instructional practices university-wide mirror those in the already well-documented STEM field.

\section{Methodology}

Data regarding faculty teaching practices was collected in the fall of 2014 at the University of British Columbia Vancouver Campus (UBC-V), a large research-intensive institution, which enrols approximately 40,000 undergraduate and 10,000 graduate students. The development of the 2014 UBC Teaching Practices Survey was a collaborative effort between the Science Centre for Learning and Teaching (Skylight) and the Centre for Teaching, Learning and Technology (CTLT). As described in Briseño-Garzón, Han, Birol, Bates, \& Whitehead (2016), this survey was mainly intended to gather information to measure the impact of institutional initiatives aimed at improving the effectiveness and efficiency of teaching and learning. Also, the goal of the initial data analysis was to explore the overall teaching climate at UBC in order to inform strategic planning and decision making, both campus-wide and within Faculties.

The final instrument was the result of a comprehensive review, integration, and modification of the Lasting Education Achieved and Demonstrated (LEAD) survey, run on both the Vancouver and Okanagan UBC campuses in 2008, and of related surveys used in various institutions across North America. The survey was modified with input from faculty from across disciplines, representatives from the Provost Office, UBC Associate Deans with teaching and learning responsibilities, and staff members from UBC teaching and learning support centres. Once a final version of the survey was validated by faculty and approved by university leadership, institutional ethics review and approval was sought to conform to research standards of ethics and integrity (BREB \# H14-01879). This paper presents a secondary analysis of the original data 
collected under the aforementioned ethics protocol.

The survey instrument consisted of two sections, the first asking about teaching practices employed in the participant's largest enrolment, lowest level course, and the second asking about perceptions of teaching practices and institutional support for teaching. The instrument contained 30 questions, primarily multiple choice or Likert scales. Three open-ended questions provided participants an opportunity to share insights about the encountered challenges to teaching, factors of improvement, and suggested changes that could have a positive impact on their teaching practices. For a detailed description of the original study, survey deployment strategy, inclusion criteria, and participant recruitment please see Briseño-Garzón et al. (2016). The survey instrument can be accessed by emailing the corresponding author at birol@science.ubc.ca while an overview of the findings of the original study can be found at http://ctlt.ubc.ca/resources/tps-report/. In addition, the qualitative sections of the survey are extensively analysed and discussed elsewhere (Briseño-Garzón et al., 2016). The present article represents a secondary analysis of the quantitative data originally collected, for which time spent lecturing was used as the main variable of interest to provide further insights.

\section{Data Analysis}

The 2014 UBC-V Teaching Practice Survey collected 1177 valid, consenting participant responses across all 11 Faculties at UBC-V. The institutional response rate was approximately $24 \%$, ranging from $14 \%$ to $68 \%$ across Faculties. The sample size was confirmed to be representative of the UBC-V population when compared with the data on faculty track and rank from UBC's Planning and Institutional Research Office (Figure 1).

In response to research literature characterizing faculty as either exclusively lecturing or exclusively relying on active learning approaches, we built on the methodology employed by Smith et al. (2014) who found most faculty employed a variety of instructional practices. For the purpose of the present analysis and in the survey instrument itself, the term 'lecturing' is broadly defined and includes other passive learning activities such as watching a video. The dataset was divided into four segments or quadrants based on participant responses to the question "Please indicate the approximate percentage of instructional time spent by instructor or TA presenting content (which includes lecturing, showing a video or performing a demonstration)".

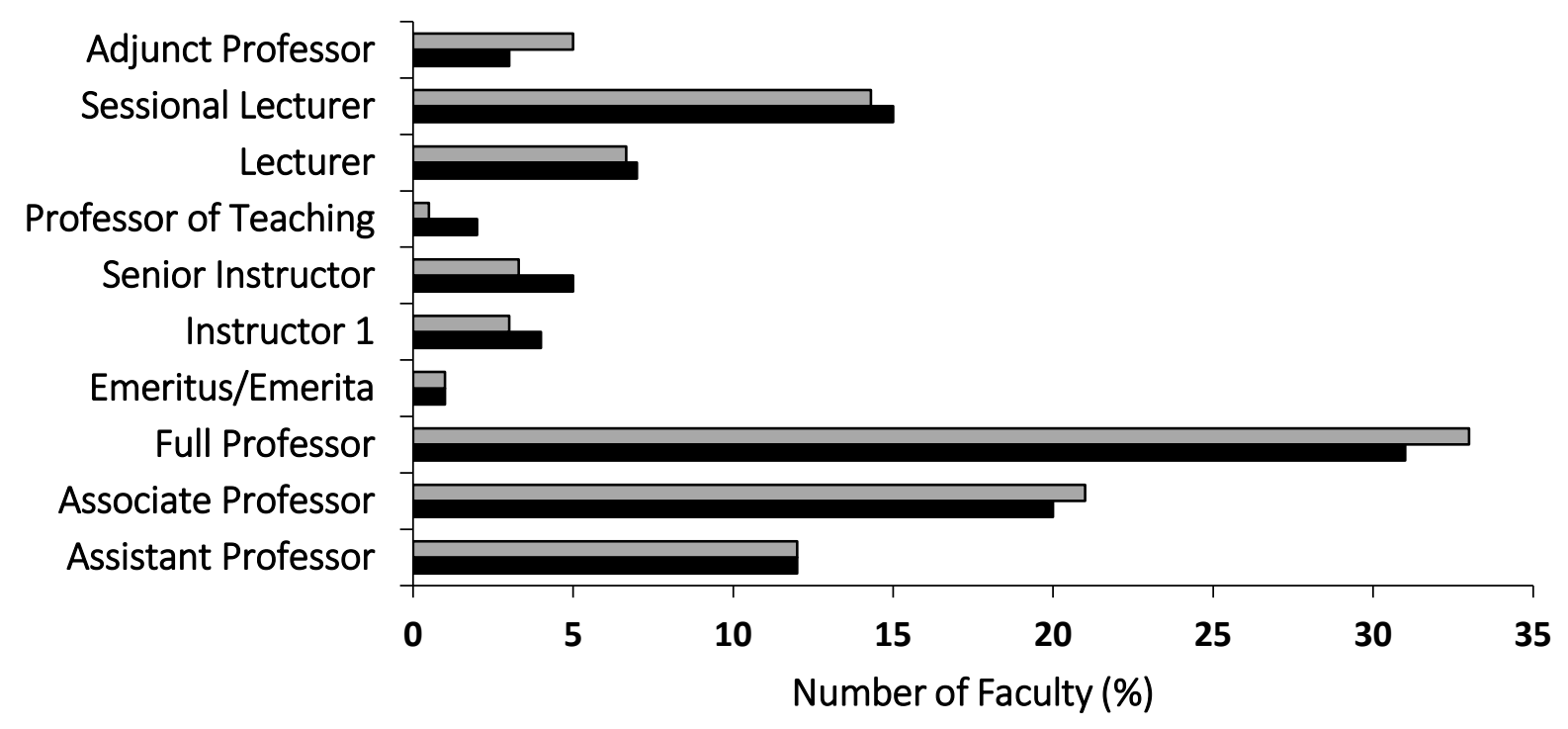

Figure 1

Participant rank and stream (BLACK) compared to UBC Vancouver population, as reported by the Planning and Institutional Research Office as of October 31, 2014 (GREY) 
In this paper, we combined "lecturing, showing a video or performing a demonstration" and referred to them as "lecturing". The four quadrants were the following:

- Quadrant 1: 0-25\% of time spent by instructor or TA on lecturing

- Quadrant 2: 26-50\% of time spent by instructor or TA on lecturing

- Quadrant 3: 51-75\% of time spent by instructor or TA on lecturing

- Quadrant 4: 76-100\% of time spent by instructor or TA on lecturing

Only those participants who consented to participate in the study and reported a total time for all activities equaling $100 \%$ are included in this analysis; this equals 891 responses across 11 Faculties.

Descriptive statistics were generated for all multiple choice and Likert-scale questions. Once participants were grouped in quadrants, we conducted a comparative analysis of survey responses (one-way ANOVA followed by Tukey HSD) by quadrant in order to explore the ways in which teaching practices and perceptions vary between participants who spend minimal and extensive time lecturing. Specifically, we examined differences in course characteristics and faculty demographics, both in-class teaching practices and expectations for outof-class student activities, responsibilities assigned to teaching assistants, participation in professional development opportunities, perceptions of the effectiveness of various teaching practices, and perceptions of institutional support for teaching.

\section{Results and Discussion}

After dividing the responses into four quadrants based on the reported percent time spent lecturing (Table 1 ), it is apparent that considerably more survey participants spend minimal time lecturing (quadrant 1) than those who reported lecturing extensively (quadrant 4). There is also a notable increase in the average class size across quadrants.

\section{Class Size and Course Level}

Participants in this study reported a wide range of class sizes in each quadrant as evidenced by the large standard deviations (Table 1). Our analysis indicates a weak positive but significant correlation between class size and percent of time spent lecturing (Pearson's $r=0.278, p<0.05$ ) for the aggregate data (Figure 2a). Lammers and Murphy (2002) found a stronger correlation between class size and the percent of time the instructor was the "only one actively involved" (Pearson's $r=0.45, p<0.001$ ). Smith et al. (2014), whose research was limited to STEM fields, reported a slightly weaker correlation between class

Table 1

Distribution of participants across quadrants

\begin{tabular}{cccc}
\hline Quadrant & $\begin{array}{c}\text { Time Lecturing } \\
\text { (\%) }\end{array}$ & Number of Participants & $\begin{array}{c}\text { Average Number of Students } \\
\text { (+/- St. Dev.) }\end{array}$ \\
\hline 1 & $0-25$ & 264 & $62(+/-71)$ \\
2 & $26-50$ & 239 & $78(+/-81)$ \\
3 & $51-75$ & 240 & $107(+/-86)$ \\
4 & $76-100$ & 148 & $132(+/-101)$ \\
\hline
\end{tabular}



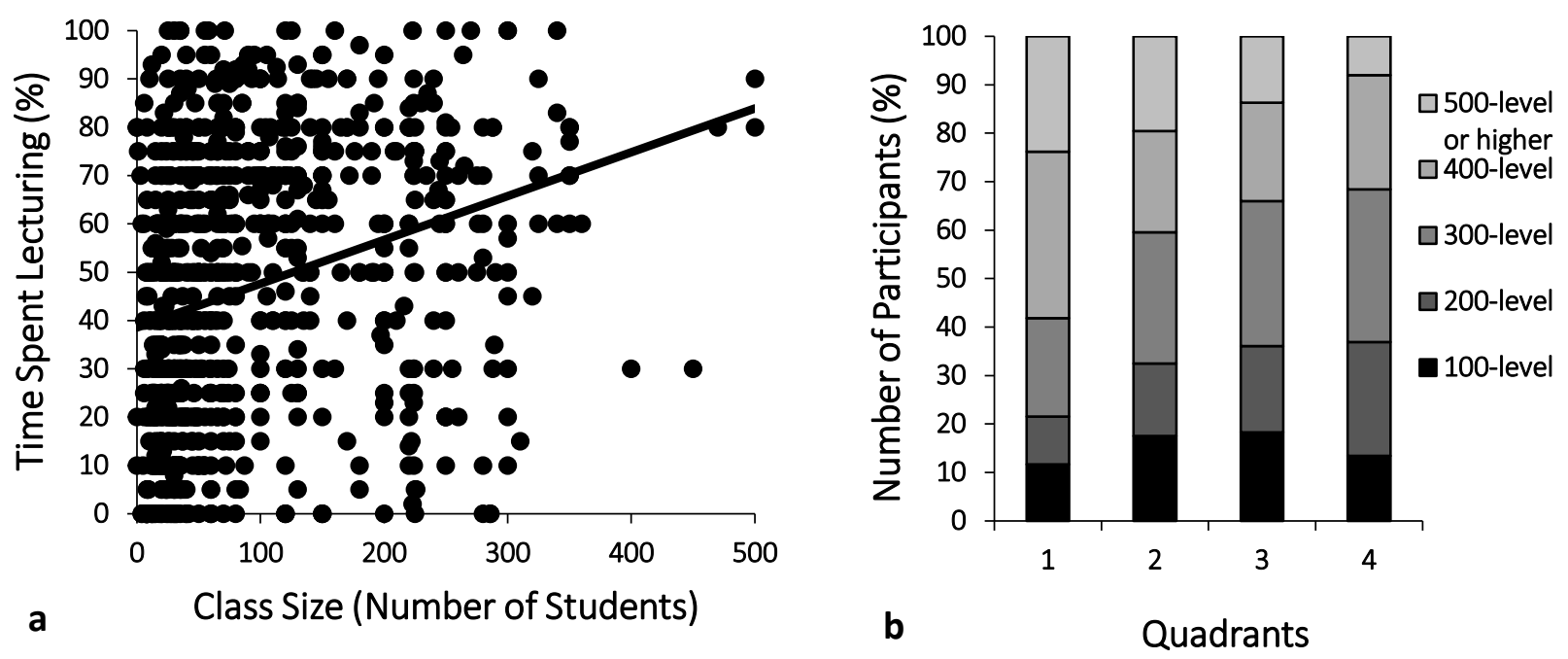

Figure 2

Distribution of class size and courses taught by participants

size and the percent of time spent presenting (Pearson's $r=0.401, p<0.05$ ). Analysis of the UBC$\mathrm{V}$ data for Science only indicates an even weaker positive but significant correlation between class size and percent of time spent lecturing (Pearson's $r=0$. $216, p<0.05)$. The difference between these studies and our results might be due to the fact that the Lammers and Murphy study was conducted at a midsize US institution and Smith et al.'s study was based solely on STEM courses at one small US institution, while the data in our analysis is from a large, researchintensive institution and is institution-wide including multiple disciplines.

The distribution of the course levels across quadrants is shown in Figure 2b. Although the percentage of upper-level courses (400- and 500level) was slightly higher in quadrant 1 than others, 100-level courses are relatively evenly distributed across quadrants. Since upper-level courses tend to focus on analysis and synthesis of knowledge, this finding is consistent with earlier findings reporting that lecture may be more appropriate in lower level courses where the objective seems to commonly be the learning of factual information (Bligh, 2000; Costin, 1972). We hypothesize the fairly flat distribution of 100-level courses across the quadrants reflects the widespread focus in higher education on the first-year experience.

\section{Faculty Teaching Experience and} Stream

Years of teaching experience (Figure 3) reported by participants was equally distributed across quadrants and included representation in all options offered, ranging from less than one to 20 and more years. The distribution of participants across UBC-V's two tenure streams, one emphasizing research and the other emphasizing teaching, along with contract faculty is presented in Figure 4. We found that all quadrants have roughly the same distribution across the categories provided for years of teaching experience, with faculty having between 15 and 19 years of experience showing the most variation across quadrants and that there was no relationship between years of teaching experience and the use of lecture. However, there was a significant difference in the distribution of research and contract faculty between quadrants $1 \& 3$ and $1 \& 4$. As the percent of time spent on lecturing increased (from quadrant 1 to 4 ), the number of research faculty represented in the quadrant significantly increased while the number of contract faculty significantly decreased. There was no statistical difference in the distribution of teaching faculty across quadrants. 


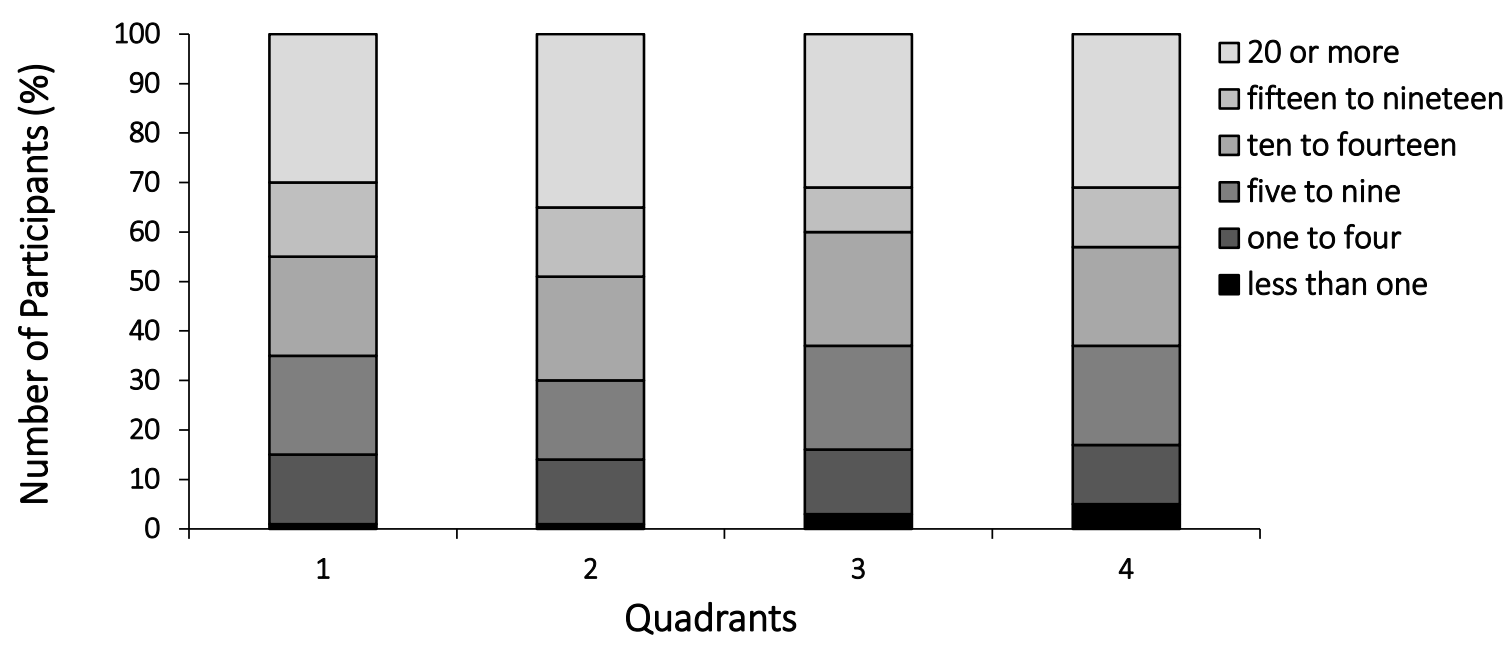

Figure 3

Distribution of participants by years of teaching experience

\section{Perceptions of Effectiveness of Active Learning and Lecturing}

We asked participants about their perceptions of active learning and lecture for the promotion of student learning. Our survey did not provide a definition of the term "active learning" because of the variety of practices employed in disciplines and concerns a definition would be constraining.
Participants across all quadrants were more likely to agree or strongly agree that "active learning was an effective way to promote student learning" than to agree with the same statement in relation to lecture (Figures 5a and 5b). However, we see opposite response patterns for these two questions. Participants in quadrant 1 are considerably more likely than those in quadrant 4 to strongly agree that "active learning is an effective way to promote student learning” (74\% versus $41 \%)$ (Figure 5a). While

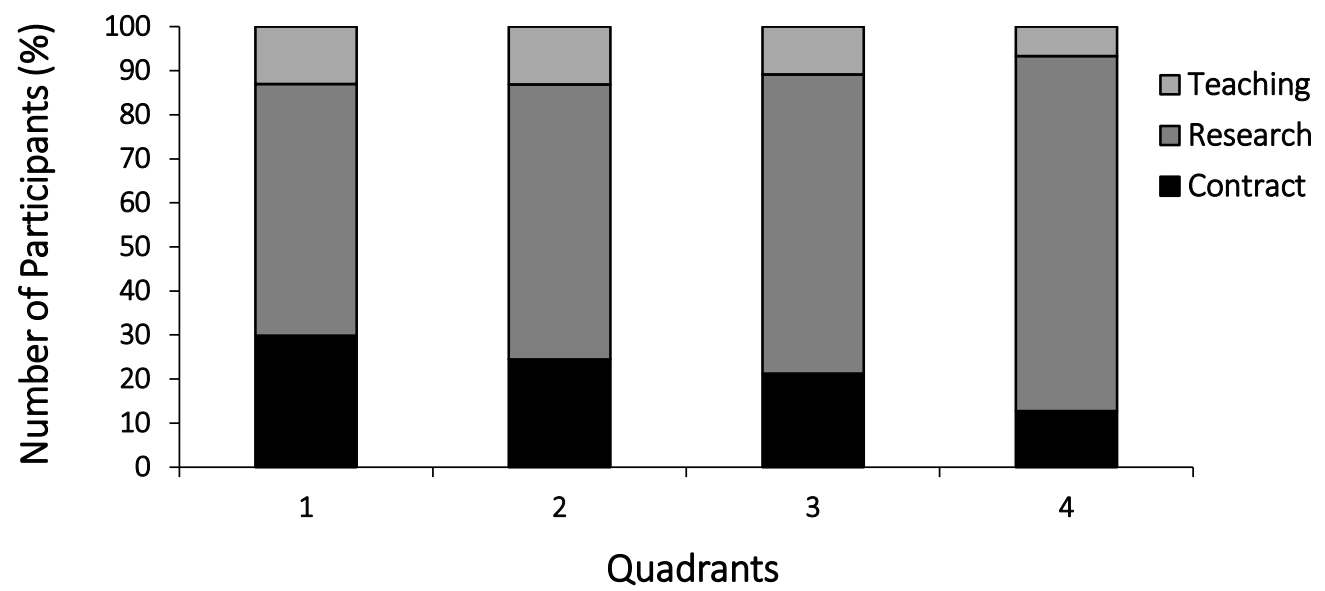

Figure 4

Distribution of participants by stream ${ }^{1}$

\footnotetext{
${ }^{1}$ A significant difference (one-way ANOVA, Tukey HSD, $p<0.05$ ) between quadrants $1 \& 3$ and $1 \& 4$ regarding the number of research faculty and contract faculty. No significant difference in the number of teaching faculty across quadrants.
} 


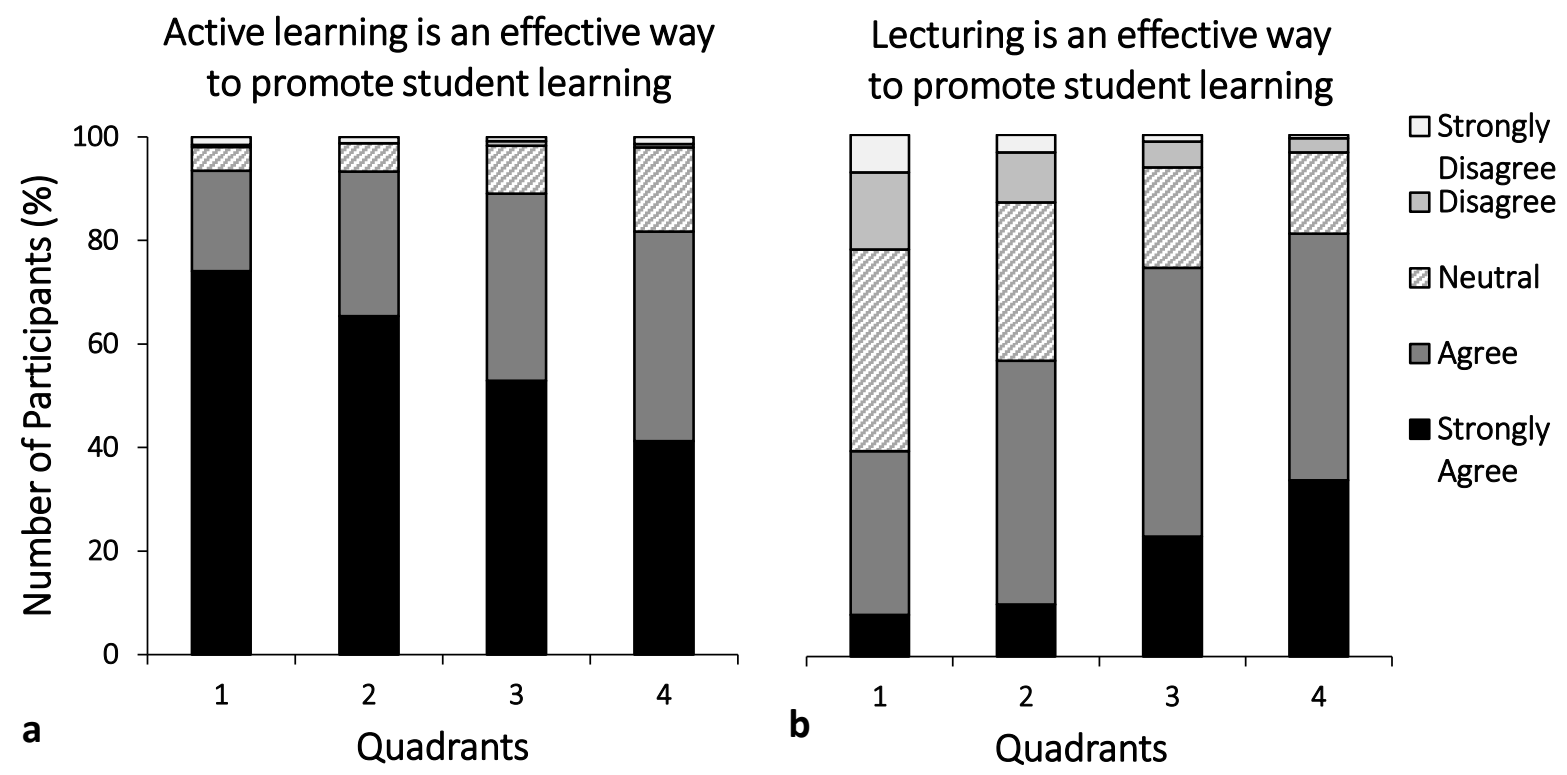

Figure 5

Perceptions of the effectiveness of active learning and lecturing

participants in quadrant 4 are considerably more likely than those in quadrant 1 to strongly agree that "lecture is an effective way to promote student learning" (34\% versus $8 \%$ ) (Figure $5 \mathrm{~b}$ ).

It is notable, however, that participant perceptions of the effectiveness of lecture and active learning do not necessarily align with their practices. Despite devoting $75 \%$ or more of their classroom time to lecture, $19 \%$ of participants in quadrant 4 do not agree with the statement "Lecture is an effective way to promote student learning". In addition, despite spending minimal time lecturing, 39\% of those in quadrant 1 agree and strongly agree with lecture being an effective way to promote student learning. Further, $82 \%$ of participants in quadrant 4 , despite spending the vast majority of their classroom time lecturing, either agreed or strongly agreed that active learning was effective. This echoes the findings of Goffe and Kauper (2014) who report some faculty choose to lecture despite beliefs that other practices may be more effective. There could be practical reasons for not choosing active learning techniques. In our previous study, the qualitative responses to the question "Briefly describe what you consider to be the biggest challenge to your teaching" revealed workload and lack of time, increasing class sizes, and balancing the delivery of content with the implementation of active learning techniques as the most prevalent challenges faculty face. A combination of these factors could explain why, despite the overwhelming positive perception of the value of active learning, faculty do not broadly implement active learning techniques (Briseño-Garzón, et al., 2016).

\section{In-Class Teaching Practices}

Overall, participants reported dedicating an average of $46 \%(S D+/-28)$ of classroom time to lecturing. Few participants reported spending more than $90 \%$ of their time on lecturing (4\%) and only 16 participants $(<2 \%)$ reported using lecture exclusively.

Participants were also asked to report percent of time on other in-class activities including class discussion, student-led activities, problem-solving, peer review, and assessments. As expected given the relationship between these variables, the average percent time spent on in-class activities other than lecturing decreased as the percent time spent on lecturing increased (Figure 6). Participants in all four quadrants reported using most of their non-lecture time for "whole class or small group discussion" with 
the reported percent of time decreasing proportionally across quadrants 1 to 4 . A similar pattern was noted in the other categories, with the exception of "Students completing assessments", which showed a relatively flat distribution across categories and had an overall average of $5 \%$ of time with a standard deviation of 6.3.

To account for the relationship between lecturing and the other variables, we recalculated the average percent time spent on in-class activities outside of lecturing (i.e., 100 minus $\%$ time spent on lecturing $=$ remaining time for other in-class activities) (Figure 7). Based on this analysis we find, even though quadrant 1 dedicates approximately $25 \%$ more classroom time to discussion, quadrant 4 spends proportionally $6 \%$ more of the remaining classroom time on discussion. Further, while the overall percent time spent on assessment is roughly even across quadrants, quadrant 4 spends a considerably larger proportion of non-lecture time on assessments $(-28 \%)$ compared to quadrant $1(\neg 7 \%)$. Looking at the distribution of remaining time within a quadrant and across activities, we see that participants in quadrant 1 reported a variety of activities with each practice averaging more than 5\% of the remaining time. Consistent with Smith et al.'s (2014) observation of a wide range of teaching practices being employed by faculty, we also see all categories reported in quadrant 4 . However, there is a greater variation in the time spent in different categories with a minimal proportion of remaining time spent on the categories characterizing students as knowledge makers ("student led activities", 6\%) and as a source of expertise ("peer review and feedback", $1 \%)$.

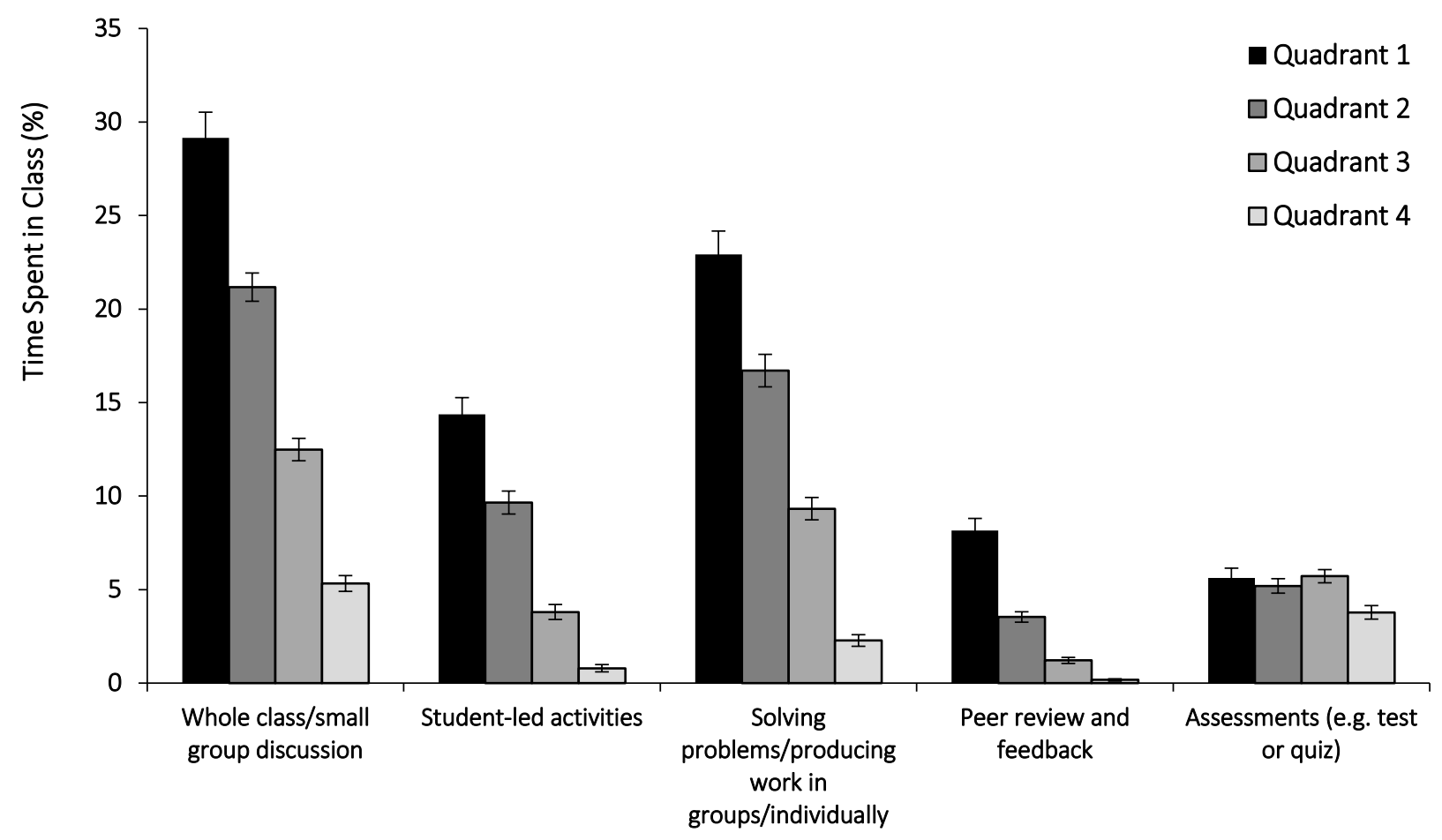

Figure 6

Average percent time spent on in-class activities (lecturing not shown) ${ }^{2}$

\footnotetext{
${ }^{2}$ Significant difference (one-way ANOVA, Tukey HSD, $p<0.05$ ) between most quadrants for all activities except for peer review and feedback for quadrants $3 \& 4$, and for assessment for quadrants $1 \& 2,1 \& 3,2 \& 3,3 \& 4$. Error bars represent standard error of the mean.
} 


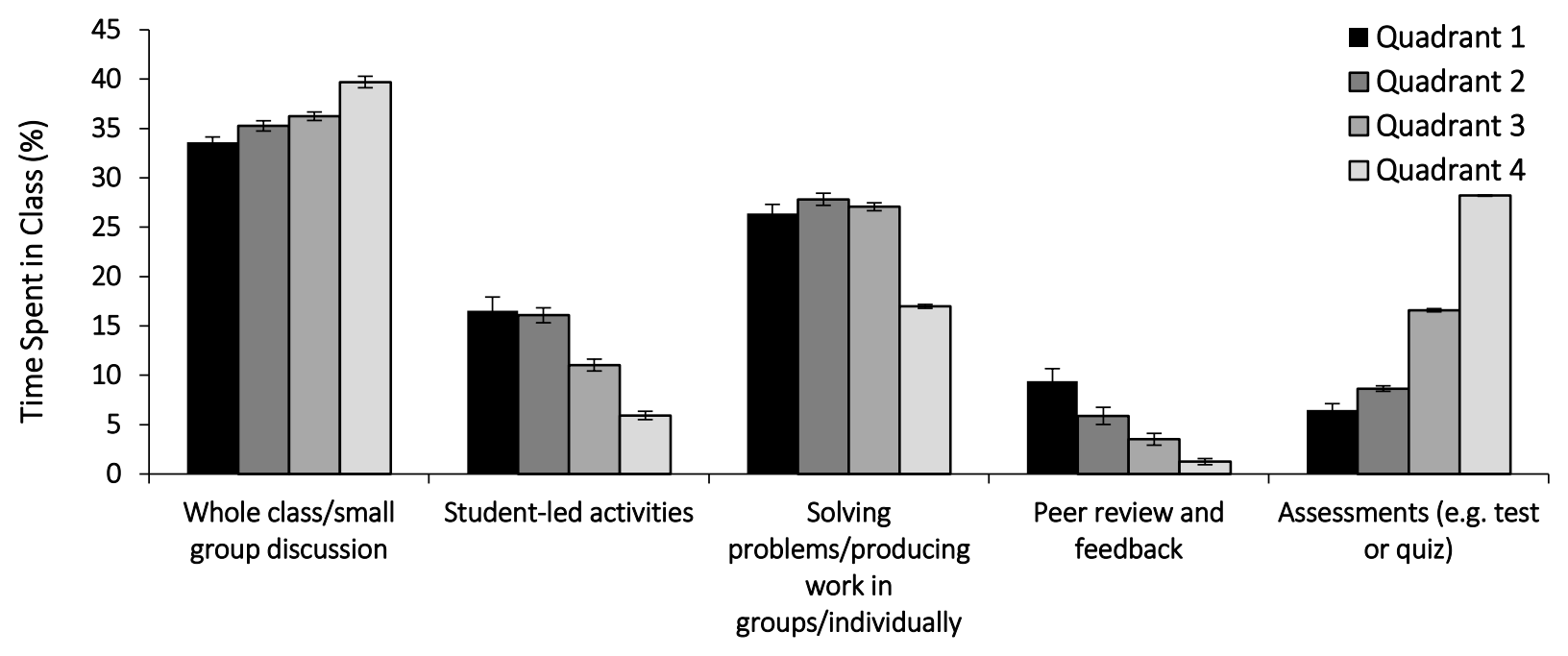

Figure 7

Average percent time spent on in-class activities (lecturing not shown), recalculated to exclude lecturing time from the total (i.e., 100 - \% time spent on lecturing = remaining time for other in-class activities)

\section{Expectations for Students Out-of-Class}

Participants were also asked to indicate the activities they expected students to complete outside of class (Figures 8 and 9). There was no significant difference across quadrants in participants reporting the expectation for students to review material with no assessment of understanding before class. However, there was a significant difference (one-way ANOVA, Tukey HSD, $p<0.05$ ) between most quadrants regarding expectations for students to review material with assessment before class, except quadrants 1 and 2 and quadrants 1 through 3 (Figure 8). Given the role pre-class assessments play in flipped or just-intime teaching, this may suggest participants in quadrants 1 through 3 implemented these practices more often than participants in quadrant 4. Interestingly, we see a different pattern in the reported expectations regarding "problem sets, homework or worksheets" that do and do not contribute to a course grade. Here, participants in quadrant 1 were markedly less likely to expect students to complete these compared to participants in other quadrants. There was no significant difference across quadrants in the expectation for students to complete "problem sets, homework or worksheets" that do not contribute to a course grade.

Across the remaining activities listed, we see a clear pattern emerge in the responses for participants within quadrants (Figure 9). Participants in quadrants 1 and 2 were more likely than participants in quadrants 3 and 4 to expect students to complete any of the activities listed, with the most dramatic differences in expectations for "group assignments" (a difference of 44\% from quadrant 1 to 4), "reflective writing" (a difference of $43 \%$ from quadrant 1 to 4 ), and "individual projects/work" (a difference of $35 \%$ from quadrant 1 to 4 ) (one-way ANOVA, Tukey HSD, $p<0.05$ ). The difference in percent of participants in quadrants 1 and 4, choosing from a variety of out-of-class activities, suggested a clear distinction between the two groups in their expectations for how students will spend their time outside the classroom. Participants in quadrant 1 expected students to engage in a variety of out-of-class activities, whereas participants in quadrant 4 were most likely to expect their students only review materials or solve problem sets. We found these responses consistent with their in-class responses in that participants in quadrant 1 consistently employed more student-centred teaching practices. 


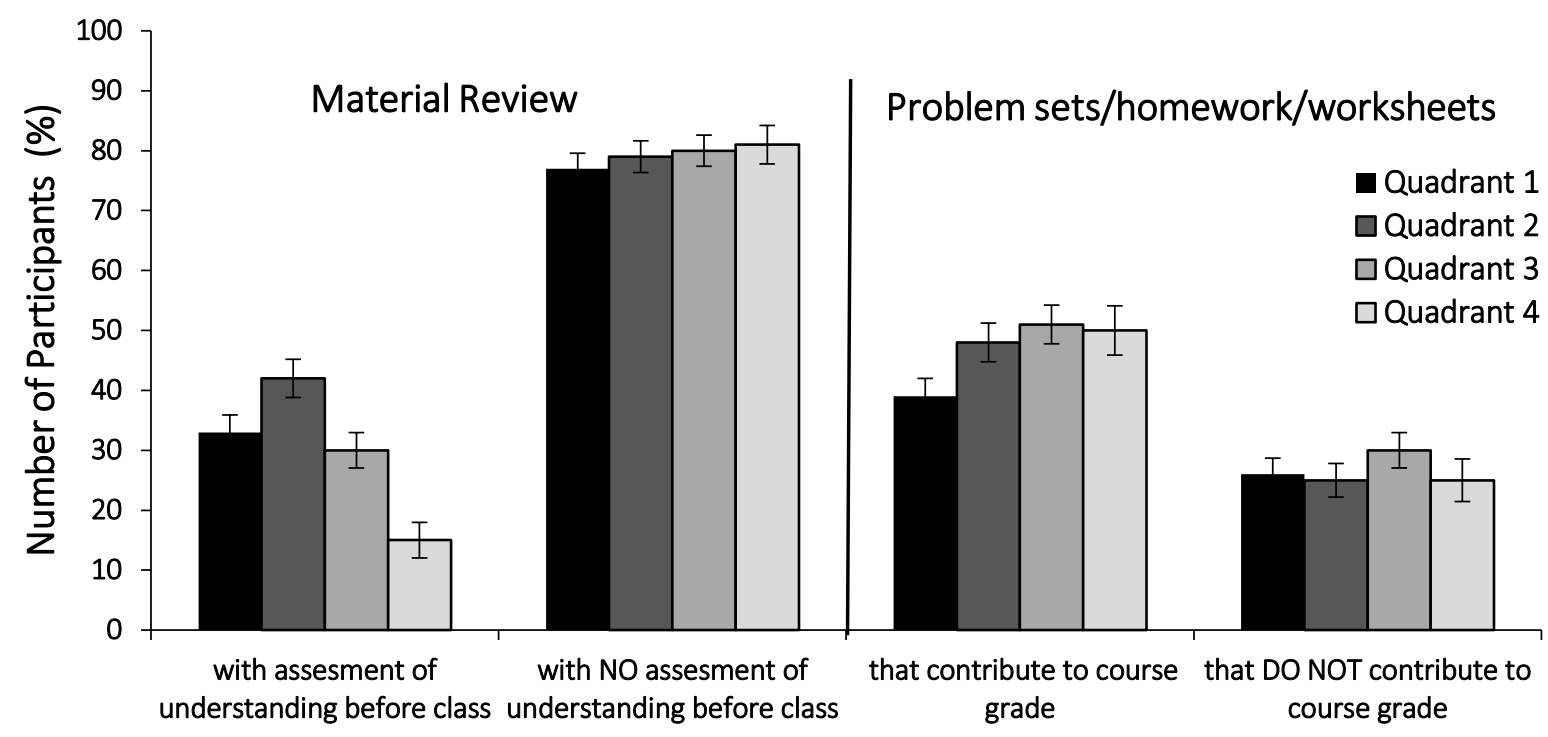

Figure 8

Out-of-class activities involving material review and homework ${ }^{3}$

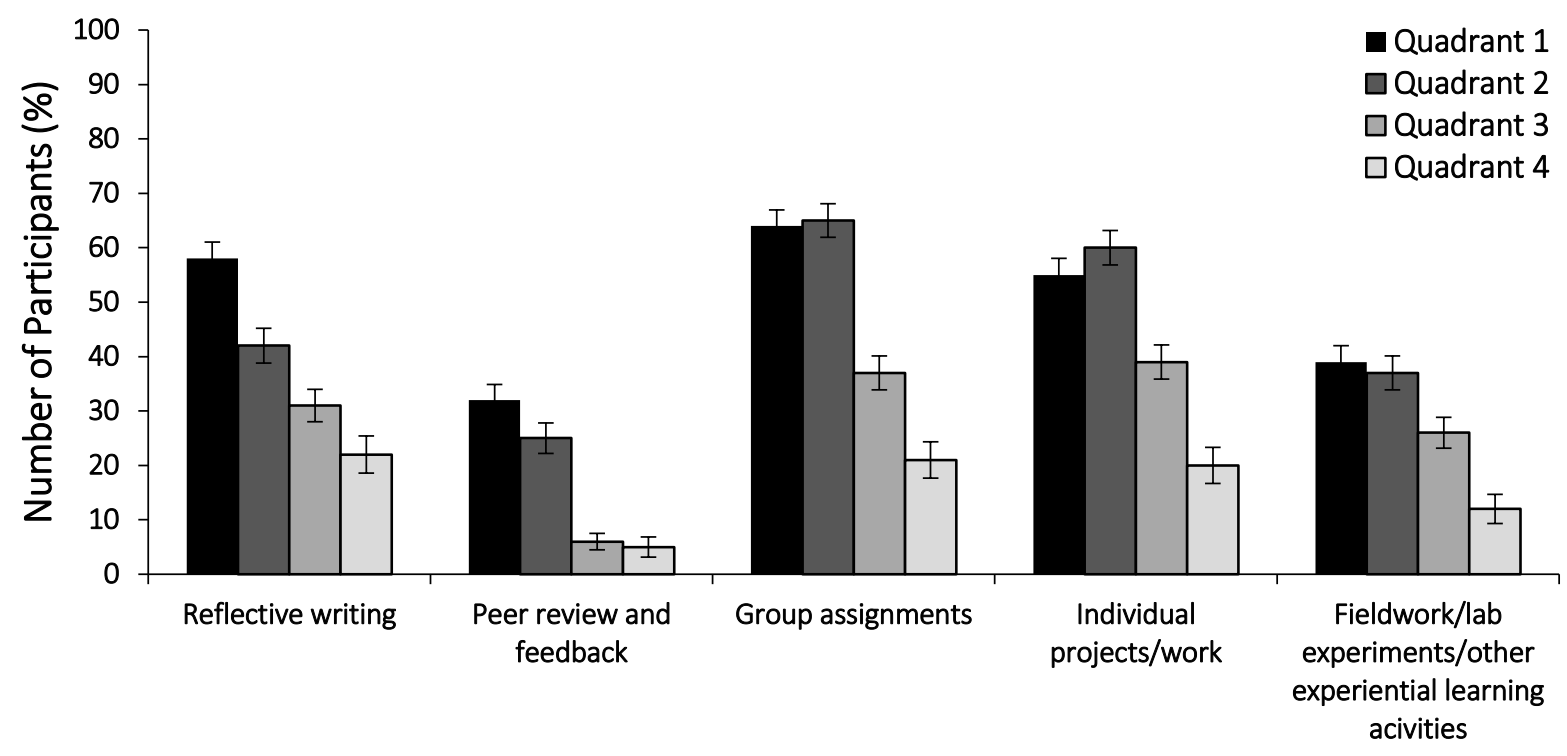

Figure 9

Other out-of-class activities ${ }^{4}$

\footnotetext{
${ }^{3}$ Significant differences (one-way ANOVA, Tukey HSD, $p<0.05$ ) were found between quadrants $1 \& 4,2 \& 3,2 \& 4$ and $3 \& 4$ for material review with assessment of understanding before class, and between quadrants $1 \& 3$ for problem sets that contribute to course grade. Error bars represent standard error of the mean.

${ }^{4}$ Significant difference $s(o n e-w a y ~ A N O V A$, Tukey HSD, $p<0.05$ ) were found between most quadrants except quadrants $3 \& 4$ for reflective writing, $1 \& 2$ and $3 \& 4$ for peer review and feedback, 1 \& 2 for individual projects and group assignments, 1 \& 2 and $2 \& 3$ for field work. Error bars represent standard error of the mean.
} 


\section{Responsibilities Assigned to Teaching Assistants}

As Table 2 shows, the percent of participants reporting having Teaching Assistants (TAs) ranges from $44 \%$ in quadrant 1 to $76 \%$ in quadrant 4 . This was not surprising given that many Faculties base TA allocation on class size, which increased from quadrant 1 to 4 . Participants across the quadrants expected TAs to support a wide range of activities and there was no relationship between the kind of TA support and class size.

Participants who reported having TAs for their courses were also asked to indicate their expectations for TAs (Figure 10). Participants in quadrants 1 and 2 reported expecting their TAs to "help to facilitate instructional activities" significantly more often than participants in quadrants 3 and 4 (one-way ANOVA, Tukey HSD, $p<0.05$ ). However, participants in quadrant 2 were most likely to report expecting their TAs to be "responsible for delivering some course instruction" and were more likely to view TAs as sources of expertise and/or faculty in training. Interestingly, participants in quadrant 1 were the least likely to expect TAs to assume responsibilities outside class meetings, to mark homework, mark exams, or provide student support outside scheduled hours. Because TA time is limited, this may be due to the increased expectations during class meetings. In addition, in large enrolment courses, some faculties employ TAs whose only responsibility is marking.
Participants in quadrants 2 through 4 expected their TAs to mark exams and papers and provide support to students beyond office hours significantly more than participants in quadrant 1 (one-way ANOVA, Tukey HSD, $p<0.05$ ). This is not surprising considering the activities (in-class and out-of-class, as discussed earlier) that participants in these quadrants chose for their students. Note that participants in quadrant 1 chose consistently more inclass activities (student-led activities, peer review, and feedback) for their students that required them to interact with each other. Although many participants reported seeking feedback from their TAs when making instructional decisions, there was no significant difference across quadrants.

\section{Participation in Professional Development Opportunities}

Participants were asked about their participation in the professional development opportunities based on a predefined list (Table 3). Across all quadrants, participants were most likely to attend teaching development events such as workshops and seminars (average of $75 \%$ across quadrants). All quadrants reported high participation in these events with the highest participation rate in quadrant $2(81 \%)$ and the lowest in quadrant 4 (70\%). Participation in teaching and learning conferences and scholarly

Table 2

Teaching assistant allocation

\begin{tabular}{ccc}
\hline Quadrant & Time Lecturing (\%) & Teaching Assistants \\
\hline 1 & $0-25$ & 44 \\
2 & $26-50$ & 63 \\
3 & $51-75$ & 69 \\
4 & $76-100$ & 76 \\
\hline
\end{tabular}




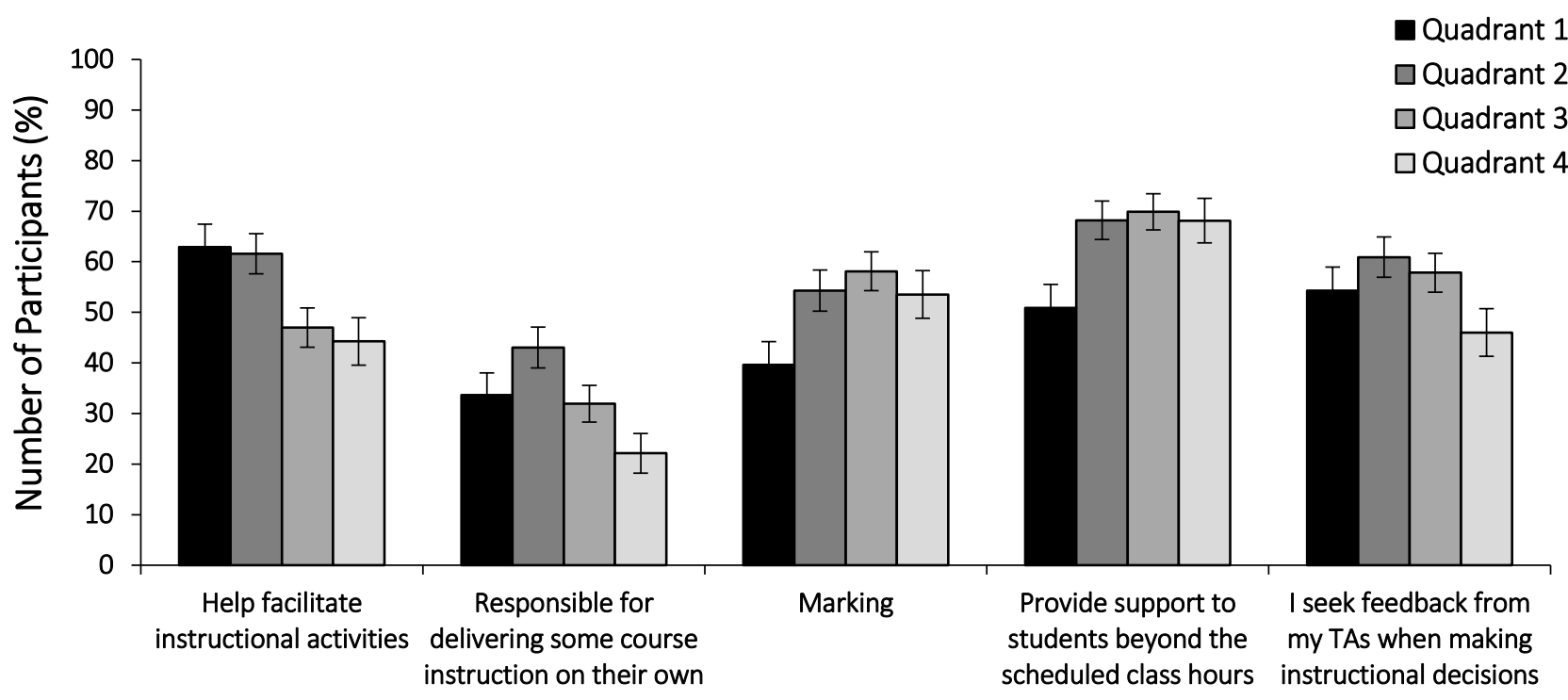

Figure 10

Expectations for Teaching Assistants 5

Table 3

Professional development activities

\begin{tabular}{lcccc}
\hline Professional Development & \multicolumn{4}{c}{ Quadrant } \\
& $\mathbf{1}$ & $\mathbf{2}$ & $\mathbf{3}$ & $\mathbf{4}$ \\
\hline $\begin{array}{l}\text { Teaching development events (i.e., talks, } \\
\text { workshops, seminars) (\%) }\end{array}$ & 76 & 81 & 73 & 70 \\
$\begin{array}{l}\text { Teaching and learning conferences (\%) } \\
\text { A cohort of scholars focused on teaching }\end{array}$ & 60 & 49 & 38 & 36 \\
and learning (\%) & 52 & 50 & 36 & 32
\end{tabular}

\footnotetext{
${ }^{5}$ Significant difference (one-way ANOVA, Tukey HSD, $p<0.05$ ) between quadrants $1 \& 3,1 \& 4,2 \& 3$, and 2 \& 4 for helping with facilitation of activities, between quadrants $2 \& 4$ for delivering some course instruction, between quadrants 1 \& 3 for marking, between quadrants 1 \& 2,1 \& 3 and $1 \& 4$ for providing support beyond class. Error bars represent standard error of the mean.
} 
cohorts varied more widely, with quadrant 1 reporting the highest levels of participation and quadrant 4 the lowest in both categories. The participation in a "cohort of scholars focused on teaching and learning" was the least pursued option among the professional development opportunities presented (average of $43 \%$ across quadrants).

\section{Perceptions of the Institutional Value and Support for Teaching}

While the majority of participants across quadrants agreed with the statement "institutional leadership recognizes the importance of teaching", there was a distinct difference in the response patterns from participants in quadrants 1 and 2 and those in quadrants 3 and 4 (Figure 11). Participants in quadrant 1 reported overall agreement at $60 \%$, while participants in quadrant 4 reported overall agreement at $94 \%$, resulting in a difference in overall agreement of $34 \%$. It is not possible for us to offer an explanation for this differential with the current data set and its investigation is beyond the scope of this study. However, it is interesting to highlight that two similar questions-"my Faculty recognizes the importance of teaching" and "my Department recognizes the importance of teaching"-did not result in a similar response pattern. The difference in overall agreement between quadrant 1 and quadrant 4 for the Faculty question was only $8 \%$ and the difference for the Department question was $4 \%$.

\section{Conclusions}

The goal of this study was three-fold. First, we sought to determine whether a range of instructional practices were employed across a large researchintensive Canadian institution or whether specific practices emerge as dominant. Second, we sought to describe the implications of minimal and extensive time lecturing on other instructional practices and faculty expectations. And third, we investigated differences in the uptake of professional development and perceptions of institutional support for teaching among faculty who spend minimal and extensive time lecturing. We used data that was originally collected in an earlier study (Briseño-Garzón, et al., 2016) and analysed it based on "time spent lecturing" as the main variable of interest. Our participants were representative of the institution's population with respect to stream and rank; however, the methodological choices we employed pose limitations to the extent in which we can go beyond a descriptive approach in the presentation of our findings.

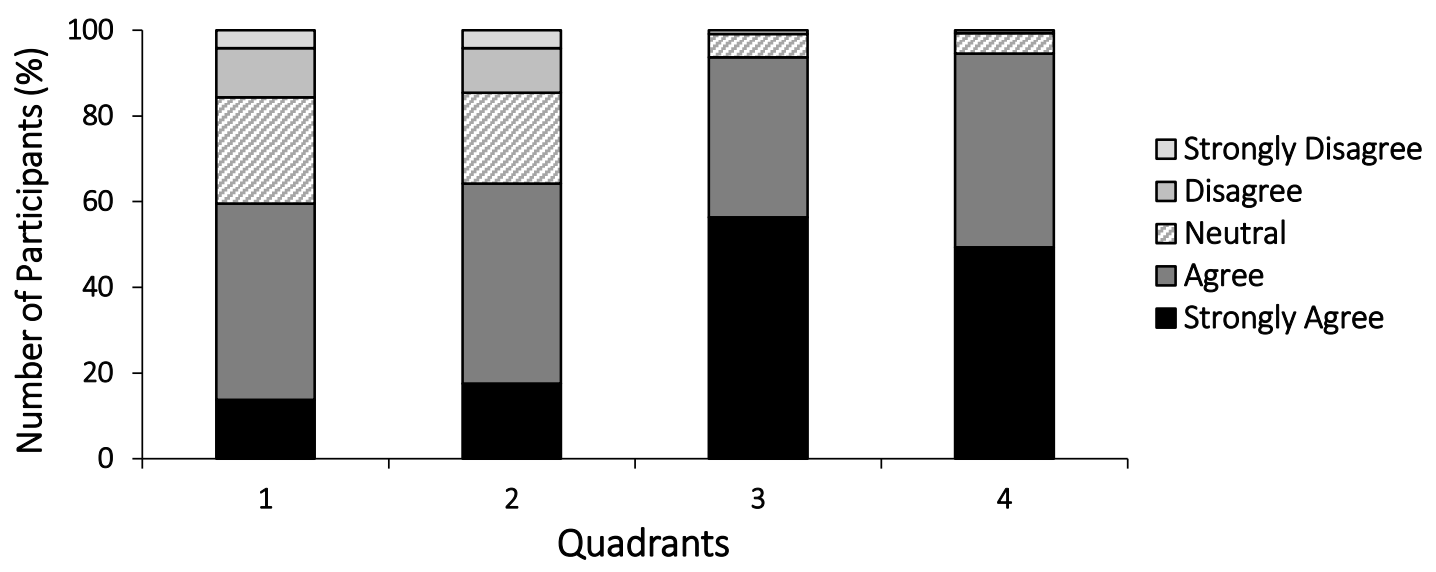

Figure 11

Perceptions of institutional leadership recognizing the importance of teaching 
Prior research on teaching practices in higher education (Kane et al, 2002; Richardson, 1996) noted the limitations of surveys in capturing beliefs and perceptions around teaching practices. In our study, some participants reported feeling constrained by having to report specifically and solely on teaching practices on their highest enrolment, lowest level course. They indicated that their practices in higher enrolment courses differed from their lower enrolment courses and that the highest enrolment course was not necessarily reflective of their overall teaching practice. In addition, since we were specifically interested in the institution-wide teaching practices as opposed to establishing a relationship between discipline and preferred instructional practices, we combined responses from all faculties/disciplines into one aggregate data pool. As a result, we were unable to explore the previously reported disciplinary differences in the nature of teaching (e.g., Neumann, 2001; Theilens, 1987) or discipline specific values and cultures (Neumann, 2001).

The data collected also did not allow us to investigate the relationships between individual faculty members' philosophies around teaching and learning, and teaching practices. These factors may explain the diverse practices that are being employed by our faculty. A further limitation is that the findings in this paper are drawn exclusively from selfreports (i.e., participant responses) rather than triangulating or complementing our data set with other forms of data such as classroom observations. There is also the possibility that participant responses were influenced by their perceptions of the "right" answer and may not accurately reflect their actual perceptions or practices. In this regard it is worth mentioning there was a conscious effort to portray both lecture and active learning in value-neutral terms in the survey as multiple parties involved in the development hold the belief that either practice may be effective in the proper context.

Contrary to earlier research (Lammers \& Murphy, 2002; Mulryan-Kyne, 2010; Smith et al., 2014; Thielens, 1987) our findings indicate a very weak correlation between class size and lecturing. Our previous findings suggest that workload may be one of the most likely reasons for faculty to default to lecture as their instructional method. We reported elsewhere (Briseño-Garzón et al., 2016) that in their open responses faculty identified workload and competing demands as most important challenges to their teaching. Recognizing that preparing to teach using alternative pedagogical approaches can be timeconsuming, particularly for the first few iterations, faculty may employ lecture due to concerns about the time required to explore and experiment with different pedagogical approaches (Goffe \& Kauper, 2014). In fact, our findings indicate that, irrespective of how much time participants spent lecturing (across quadrants), a very high proportion of all participants believe in the effectiveness of active learning to promote student learning.

Our findings show that years of teaching experience is not related to the amount of time faculty choose to lecture and that research faculty are more likely to engage in this teaching practice than their teaching stream and contract colleagues. Interestingly, faculty with less than one year of teaching experience spent considerably more classroom time lecturing than employing active learning approaches. We also see differences in the average amount of time spent lecturing by course level, with a peak in second-year courses. This may be a result of a broad institutional commitment to enriched educational experiences which include small first-year seminar courses with minimal classroom time devoted to lecture (Sens \& Fryer, 2012).

Furthermore, our findings also suggest that a wide range of teaching practices are employed in our institution and that a decision to lecture extensively or minimally does not preclude faculty from adopting other pedagogical approaches. This expands on the research of Smith et al., (2014) which focuses on STEM courses in a small US institution. We found significant differences in the practices employed in and out-of-class when those who spend less time lecturing and more time lecturing are compared. Clearly, faculty who spend less time lecturing have more time to engage in other activities that emphasize student engagement.

Our findings also indicate that teaching assistants are expected to support a wide range of 
activities irrespective of class size. However, there are significant differences in expectations from TAs depending on the amount of time lecturing. For example, those who lecture less tend to expect their TAs to help with facilitating instructional activities more than their counterparts, while those who lecture more tend to expect their TAs to provide outside of class support with office hours. This requires wellestablished professional development opportunities and programs for TAs to be able to adopt such diverse needs.

When the types of professional development activities are compared, teaching development events (talks, workshops, and seminars) are more likely to be attended than teaching and learning conferences or joining a cohort of scholars focused on teaching and learning. This is perhaps not surprising considering the time commitment required to be a contributing member of a cohort compared to attending a onehour presentation.

While it might seem paradoxical, we found that faculty who report spending more time lecturing (quadrants $3 \& 4$ ) were considerably more likely to agree that teaching was recognized and valued by the institutional leadership than their colleagues who spent less time lecturing (quadrants $1 \& 2$ ). This apparent disconnect could indicate that the ways in which the institution communicates its values indirectly prioritize lecture over active learning practices. Large class sizes, where we see substantially more classroom time devoted to lecture, may be viewed as more economically efficient and, as mentioned earlier, are "rewarded" with additional resources such as TAs. This may suggest that there could be implications for what the institution communicates to faculty and how what is communicated aligns with promotion and tenure processes and policies.

It is important to highlight that our study did not explore student learning directly, and therefore, our findings are not indicative of the effectiveness of any given teaching practice. More research that allows us to better understand the conditions under which lecture is or is not an effective approach to promote student learning could help us support faculty who choose to lecture in a more meaningful way. We strongly believe, nonetheless, that our study contributes to gaining a better understanding of the current teaching climate and culture at large Canadian research-intensive institutions as the first and necessary step to inform decision-making and support planning within the institution that served as the context for this study and beyond.

\section{References}

Ambrose, S. A., Bridges, M. W., DiPetro, M., Lovett, M. C., Norman, M. K., \& Mayer R. E. (2010). How learning works: Seven research-based principles for smart teaching. San Francisco, CA: Jossey-Bass.

Bain, K. (2004). What the best college teachers do. Cambridge, Mass: Harvard University Press.

Ballantyne, R., Bain, J. D., \& Packer, J. (1999). Researching university teaching in Australia: Themes and issues in academics' reflections. Studies in Higher Education, 24(2), 237-257. VIEW ITEM

Blackburn, R. T., Pellino, G. R., Boberg, A., \& O'Connell, C. (1980). Are instructional programs off-target? Current Issues in Higher Education, 1, 32-48.

Bligh, D. (2000). What's the Use of Lectures? San Francisco, CA: Jossey-Bass.

Blumberg, P. (2011). Making evidence-based practice an essential aspect of teaching. Journal of Faculty Development, 25(3), 27-32. VIEW ITEM

Boice, R. (1992). The new faculty member: Supporting and fostering professional development. San Francisco, CA: Jossey-Bass.

Briseño-Garzón, A., Han, A., Birol, G., Bates, S., \& Whitehead L. (2016). Faculty perceptions of challenges and enablers of effective teaching in a large research intensive university: 
Preliminary findings. Collected Essays on Learning and Teaching, 9, 133-144. VIEW ITEM

Buskist, W., \& Groccia, J. E. (Eds.). (2011). Evidence-based teaching. In C. M. Wehlburg (Series Ed.), New Directions for Teaching and Learning Series: Number 128. San Francisco, CA: Jossey-Bass. VIEW ITEM

Costin, F. (1972). Lecturing versus other methods of teaching: A review of research. British Journal of Educational Technology, 3(1), 4-31. VIEW ITEM

Eagan, K., Stolzenberg, E. B., Lozano, J. B., Aragon, M. C., Suchard, M. R., \& Hurtado, S. (2014). Undergraduate teaching faculty: The 20132014 HERI Faculty Survey [Monograph]. VIEW ITEM

Freeman, S., Eddy, S. L., McDonough, M., Smith, M. K., Okoroafor, N., Jordt, H., \& Wenderoth, M. P. (2014). Active learning increases student performance in science, engineering, and mathematics. Proceedings of the National Academy of Sciences of the United States of America, 111(23), 8410-8415. VIEW ITEM

Goffe, W. L., \& Kauper, D. (2014). A survey of principles instructors: Why lecture prevails. The Journal of Economic education, 45(4), 360375. VIEW ITEM

Henderson, C., Beach, A., \& Finkelstein, N. (2011). Facilitating change in undergraduate STEM instructional practices: An analytic review of the literature. Journal of Research in Science Teaching, 48(8), 952-984. VIEW ITEM

Hiebert, J., \& Stigler, J. W. (2000). A proposal for improving classroom teaching: Lessons from the TIMSS video study. The Elementary School Journal, 101(1) 3-20. VIEW ITEM
Kane, R., Sandretto, S., \& Heath, C. (2002). Telling half the story: A critical review of research on the teaching beliefs and practices of university academics. Review of Educational Research, 72(2), 177-228. VIEW ITEM

Lammers, W. J., \& Murphy, J. J. (2002). A profile of teaching techniques used in the university classroom: A descriptive profile of a US public university. Active Learning in Higher Education, 3(1), 54-67. VIEW ITEM

Lortie, D. C. (1975). Schoolteacher: A sociological study. Chicago: University of Chicago Press.

Michael, J. (2006). Where's the evidence that active learning works? Advances in Physiology Education, 30(4), 159-167. VIEW ITEM

Miller, J. W., Martineau, L. P., \& Clark, R. C. (2000). Technology infusion and higher education: Changing teaching and learning. Innovative Higher Education, 24(3), 227-241. VIEW ITEM

Mulryan-Kyne, C. (2010). Teaching large classes at college and university level: Challenges and opportunities. Teaching in Higher Education, 15(2), 175-185. VIEW ITEM

Neumann, R. (2001). Disciplinary differences and university teaching. Studies in Higher Education, 26(2), 135-146. VIEW ITEM

Nilson, L. B. (2010). Teaching at its best: A researchbased resource for college instructors ( ${ }^{\text {rd }}$ ed.). San Francisco, CA: Jossey-Bass.

Prince, M. (2004). Does active learning work? A review of the research. Journal of Engineering Education, 93(3), 223-231. VIEW ITEM

Richardson, V. (1996). The role of attitudes and beliefs in learning to teach. In J. Sikula (Ed.), Handbook of Research on Teacher Education (pp. 102-119). New York, NY: Simon \& Schuster. 
Saroyan, A., \& Snell, L. S. (1997). Variations in lecturing styles. Higher Education, 33(1), 85104. VIEW ITEM

Sens, A. \& Fryer, M. (2012). Enriched Educational Experiences at UBC: A Framework for Dialogue and Action. VIEW ITEM

Smeby, J. -C. (1996). Disciplinary differences in university teaching. Studies in Higher Education, 21(1), 69-79. VIEW ITEM

Smith, M. K., Vinson, E. L., Smith, J. A., Lewin, J. D., \& Stetzer, M. R. (2014). A campus-wide study of STEM courses: New perspectives on teaching practices and perceptions. CBE-Life Sciences Education, 13(4), 624-635. VIEW ITEM

Thielens, W., Jr., (1987). The disciplines and undergraduate lecturing. Paper presented at the annual meeting of the American Educational Research Association, Washington, D.C.

\section{Acknowledgements}

We would like to thank everyone who provided feedback and participated in the survey; Dr. Angela Redish, Vice-Provost and Associate Vice-President Enrolment and Academic Facilities, UBC-V; staff members at the Science Centre for Learning and Teaching and the Centre for Teaching, Learning and Technology; Deans and Associate Deans with teaching and learning responsibilities at UBC-V; internal collaborators Dr. Simon Bates and Dr. Lorne Whitehead; and external collaborators Dr. Jim Greer (USASK), Dr. Daniel Bernstein (KU), and Dr. Emily Miller (AAU).

\section{Biographies}

Gülnur Birol, Faculty of Science, Science Centre for Learning and Teaching, University of British Columbia, Vancouver, BC, Canada.

Adriana Briseño-Garzón, Centre for Teaching, Learning and Technology, University of British Columbia, Vancouver, BC, Canada.

Andrea Han, Centre for Teaching, Learning and Technology, University of British Columbia, Vancouver, BC, Canada. 